\title{
Study on the Function of Government in the Innovation and Development Process for SMEs in China
}

\author{
Liu Shuo \\ Department of Business Administration \\ Jilin Business and Technology College, Changchun Jilin province, China \\ Liushuo9826@163.com
}

\begin{abstract}
The government plays an important role in the innovation and development process of SMEs in china. Intuitively, government agencies have an important impact on innovation of small and medium-sized enterprises (SMEs), which through direct subsidies, tax incentives, financial support, business incubator, government procurement and the diffusion of innovation policy, and by a duty power and individual power. Further analysis showed that, the impact of government on SMEs innovation performance need to be mediated by three factors: SMEs Innovation resources input, the strength of relationship between SMEs and government, SMEs organization incentive.
\end{abstract}

Index Terms - SMEs, Innovation, Government

\section{Introduction}

Chinese industry and society is undergoing rapid changes. How to continue to innovation in response to the challenges of rapidly changing environment is our common concern. Whether it is for a country's prosperity and progress, or for the survival and development of an enterprise, innovation is an eternal theme. Chinese government had put forward the "independent innovation" slogan already. It hopes that Chinese enterprises no longer stay in the introduction and imitation of foreign advanced products and technology. China enterprises should have their own original technology and become the world leader in some industries and fields and standard setters. This is incentive and stress for the SMEs, which are numerous, small scale, and own limited resources. Only by continuous innovation could the SMEs occupy a space in competition. In the past, our understanding of innovation was limited to within an industry or a market system of an enterprise, but too much emphasis on innovation that should be spontaneous and active. However, the majority of SMEs in China are facing more challenges and problems in the process of innovation because of their endowment, innovation ability and management level, and the acquisition and capacity constraints of use external resources [1]. In recent years, whether national or local government, through various policy tools and authority to motivate enterprises' independent innovation behaviour, which improved the efficiency of innovation input. More and more people realize that the government behaviours have positive meaning to enterprise innovation. However, a lot of theoretical and empirical studies show that compared with large enterprises, SMEs innovation needs more government support but have less access to government support. From the relevant literature, only a few research about the government function in the process of the development of SMEs. What support had the Chinese government provided for the innovation of SMEs? Did these supports really conducive to innovation of SMEs?
How did government actions affect the innovation performance of SMEs? There is no clear answer to these questions. Based on relevant research, this paper would analyse how the government support to influence the innovation of SMEs.

\section{The Main Problems in the Process of Innovation and Development for SMEs}

\subsection{The definition of small and medium-sized enterprises (SMEs)}

SMEs have become an important part in the economic development of countries and an important object of academic research. The SME itself is a kind of habit of expression, and it is generally based on the scale of enterprise. Different countries for SME criteria are not the same. After the founding of new china, we adopt single quantitative standard on the definition of SME [1]. In 1962, according to the number of employees we divided enterprises into three kinds: employees below 500 are small enterprises, employees between 500 and 3000 are medium sized enterprises, employees more than 3000 are large enterprises. Since then, this standard passed through several corrections.

The new standards promulgated in June 2011in the notice file named <on the issuance of small and medium-sized enterprises designated type standard>. It was jointly issued by the Ministry of industry and information technology, the National Bureau of statistics, the national development and Reform Commission and the Ministry of Finance [2]. According to the contents of this document, we can give the classification standard of SMEs by enterprise employee number, business income, assets and other indicators and combine with industry characteristics.

Like agriculture, forest, animal husbandry and fishery operating, which income below of $¥ 200$ million are SMEs. Industrial practitioners which below 1000 people and operating income below $¥ 400$ million are SMEs. In construction industry, both the business income and total assets are below $¥ 800$ million are SMEs. Wholesales which have employees below 200 people and operating income below $¥ 800$ million are SMEs. Retailers which have employees below 300 people and operating income below $¥ 200$ million are SMEs. In accommodation and catering industry, employees below 300 people and operating income below $¥ 100$ million are SMEs. In addition, for other industries also have very specific rules. 


\subsection{The problems of innovation and development for SMEs in China}

Since the reform and opening up, Chinese SMEs had achieved rapid development. The SMEs have characteristics such as less investment, quick effect, flexible production and operation, rapid response to market changes and others. And they play positive roles in promoting the establishment of the market economy and the reform. But compared with large enterprises, SMEs are still have a lot of problems, such as not equal opportunity, shortage of funds, talents and information scarcity, competition ability is weak and so on. So the SMEs are urgent need the government to give special policy support. From the point of innovation, the SMEs of our country are mainly facing the following problems (Bi Shoufeng, Kong Xinxin, 2012; Wang Yaling, 2008) [3][4]:

(1) Lack of innovation funds. Capital investment is the foundation of innovation activities. But the SMEs in China are lack of innovation funds. On one hand, Chinese SMEs have less own funds to invest in Innovation, at the same time they are difficult to get bank loans because of the difficulties in guarantee and mortgage. On the other hand, the government's financial allocations are inclined to large state-owned enterprises. In addition, venture capital and other financing channels have not been fully utilized. Deficiencies in investment funds not only affect the innovation activities of SMEs' development, also affect the effective transformation of innovative achievements.

(2) short of innovation talent. Talent is the foundation and the power of enterprise innovation. However, compared with large enterprises, SMEs are even more in innovation talent shortage. First of all, only a few people from the entrepreneur to the general staffs have the innovation ability in the majority of SMEs. The employees' cultural level is generally low in SMEs. And they often lack the necessary skills training. Secondly, because of the limitation in scale and treatment, it is difficult to attract excellent talents for the SMEs. Especially influenced by the existing social system, most of scientific and technical personnel are more willing to stay in large stateowned enterprises and institutions. Thirdly, even if some SMEs have attracted some outstanding innovative talents, but because of the innovation environment and resource constraints, it is difficult to give full play to the talents' innovation ability.

(3) The protection of intellectual property is not enough. Intellectual property is the result of enterprise's innovation. Although the government's protection for intellectual property increased, the intellectual property theft is rampant. Especially for the SMEs, their awareness of protect the intellectual property is relatively weak and self-protection ability is low. Once the intellectual property of their creative achievement is stolen, the enterprise will suffer a fatal injury. In addition, the current laws and regulations on the protection of intellectual property are not perfect. If there are violations, the process of assertion of rights for SMEs is complicated, and the cost is large. Therefore, we cannot effectively protect intellectual property greatly affected the SMEs to increase $\mathrm{R} \& \mathrm{D}$ investment and participate in technical innovation activities.

(4) The government support less for the innovation of SMEs. The government is an important external driving force of the innovation of SMEs. The government can give support to SMEs in many aspects, funds, technology, information and financial. A lot of theoretical and empirical studies have also indicated that, compared with large enterprises, $R \quad \& \quad D$ and innovation of SMEs need more government support. But the reality is our SMEs got less support from the government affected by a variety of reasons. An empirical survey by Bi Shoufeng, Kong Xinxin (2012) showed that 54\% of mediumsized enterprises did not get the support of the government when they carry out R \& D activities, $65.1 \%$ of small enterprises did not receive government support, and $73.6 \%$ of micro enterprises did not get the support of the government.

\section{The Support from Government to the Innovation and Development of SMEs}

In recent years, governments support for the innovative activities of SMEs through a variety of ways. The SME innovation policy is the basic form of state assistance to SMEs. Innovation policy has the responsibility to lead the orientation for SMEs' innovation and development, to improve the innovation input, to optimize innovation output. By comparison, the governments of developed countries are more systematically to support SMEs' innovation. Rothwell and Zegveld (1981) had divided the government's innovation policy into four categories: innovation supply policy, innovation demand policy, innovation environment policy and innovation based policy [7]. Innovation supply policy refers to the government to provide seed money for the enterprise innovation, to provide strategic guidance for the development of the industry, and to encourage higher education institutions to provide personnel for the enterprises. Innovation demand policy refers to the local and central government to purchase the enterprise innovative products, processes and services, and help enterprises to exploit the international market. Innovation environment policy refers to the government to introduce industry related laws and regulations, formulate preferential tax, government loans, subsidies and credit guarantee for SMEs. Innovation based policy refers to the government to develop industry standards and norms, to encourage the development of intermediary industry, and encourage enterprises to innovate cooperation.

Tang Linjia et al. (2013) [8] had divided the innovation policies into six categories base on the scanning of innovation policy for SMEs in Japan, South Korea, America, Britain, Taiwan and other countries and regions.

(1) The direct subsidy policy based on R\&D. It means the government give directly support and funding to the $\mathrm{R} \&$ $\mathrm{D}$ activities.

(2) The preferential tax policy based on the government finance. It means the government provide financial incentives and tax preferential to SMEs. 
(3) The financial support policy based on venture capital. One way is the government give innovative financial support directly by its innovation investment fund or venture capital funds. Another way is the indirect financial support, including attract foreign venture capital and private venture capital to invest in domestic SMEs, to set up small business bank, to guide the private sector investment equity market in the folk, or use other government investment funds.

(4) Business incubators policy based on the cultivation. Government separately funded on the commercial feasibility of the enterprise knowledge and skills, experienced executives, new product, process or service test and early commercialization process.

(5) Market support policy based on the procurement. The government has huge purchasing power, and it can improve innovation ability dramatically for specific areas.

(6) Innovation diffusion policy based on service.

Government support the results from $R \& D$ by universities transfer to enterprises through technology related cooperation and network, in order to solve the problem of disconnect between enterprise and University.

\section{The Specific Mechanism of Government in the Innovation and Development of SMEs}

\subsection{Government behaviours can help SMEs to increase resources input and improve the innovation performance}

In the innovation development of SMEs, enterprises are the main body of innovation, universities and scientific research institutions are important sources of innovation, the government is the leader of the whole innovation system. The government's policy tools were guiding enterprises to increase investment in technological innovation resources through reallocation of resources, tax breaks, and to prevent the theft of intellectual property. On one hand, through direct subsidies, tax incentives and government procurement, the government injected large amounts of resources for the innovation of SMEs directly. These resources are equivalent to additional revenue for SMEs. On the other hand, the government also guiding and strengthening the SMEs to increase innovation resources input through financial support policy, hatching and diffusion of innovation policy. When the innovative activities of SMEs get the support of the government, SMEs will be more willing to increase the input of innovation resources. And in many times the government in support of enterprise innovation requires enterprises to provide the same or even greater proportion of investment. The resources include not only the money and other tangible assets, also including human resources and other intangible assets. Therefore, it is thought that government behaviour directly affects the SMEs' innovation resources input.

Innovation is a kind of activity which needs huge investment but has low success rate. When the SMEs get the support of the government directly or indirectly, it will increase the innovation resources, so as to improve the degree of attention to innovation activities. Especially in the process of technique innovation, once more resources being injected into innovation, SMEs will be able to provide more favourable conditions for the attraction of outstanding innovative talents. And there will be more funds to improve conditions for scientific research, and improve the product function and provide more sufficient guarantee to improve the technology content of the enterprise. And if SMEs have rich resources, they will be more easily to obtain more knowledge and information through various channels. At the same time, the increasing investment in education can enhance their learning and knowledge integration capability. The implementation of this series of activities will enable SMEs to obtain higher innovation performance.

\subsection{Government behaviours can increase the strength of the relationship between enterprises and government and then improve the innovation performance}

In China, government is the main control of social resources. So for the SMEs government can not only exercise the authority, as mentioned in the reward power, legitimate power and coercive power, may also use personal power, such as the referent power, expert power and information power.

On the one hand, the government use of power will have a positive impact on the strength of the relationship between them and the SMEs, no matter whether it use of personal power or by the authority. When a government agency to develop a series of incentives, tax policies and regulations through the use of authority, it can affect the innovative activities of SMEs. And these help to establish a good relationship between them and the SMEs. When the government staffs help SMEs to understand information about the new preferential policies about R \& D, or to help SMEs to get government funding of R \& D projects, or to get support in the process of new product development, these can help to further strengthen the relationship between the government and SMEs.

On the other hand, the government can be the bridge and link among SMEs with the education institutions, scientific research institutions and other enterprises or organizations. It will have a positive effect on the strength of the relationship between them and SMEs. Limited by their own resources and capabilities, SMEs can only cooperate with few education institutions or research institutions. At the meantime, the reality and cruel of market competition, and weak intellectual property protection, also make SMEs' innovation cooperation is very limited. Government agencies often interact frequently with a large number of local enterprises and organizations and have huge network relationships. So they can be regarded as a warehouse includes regional information, knowledge and opportunities. If the relationship between SMEs and government agencies rather closely, government agencies as a professional information network character can make the SMEs more easily access to regional network. In this way, the enterprise will indirectly connect with many parts of the region in a social network. 


\subsection{Government behaviours help SMEs to strengthen organizational incentive and then improve innovation performance}

SMEs are the main body of innovation. If they got government innovation support means to gain additional subsidies, administrative protection, policy support, competition advantage and increase profits. So SMEs must be actively cooperating with the government.

Firstly, get the support of government means a kind of encourage for SMEs' innovation. On the one hand, SMEs can get more substantial resources from support. On the other hand, it also helps enterprises to grasp the direction of innovation. Therefore, by the support SMEs will increase innovation investment, increase funding, attracting more high technology personnel, purchase of advanced scientific research equipment and encourage employees to innovate, so as to improve the efficiency of innovation.

Secondly, when the innovative activities of SMEs have the support of government, enterprises can have more sufficient resources to motivate employees. For any enterprise, the main innovation is the staff. Only properly motivated employees can have a greater potential for innovation. With rich resources means SMEs have more way to incentive their employees. Enterprises can stimulate staff's enthusiasm and creativity through different material incentive and spirit incentive, so as to improve the effect of innovation. Government policies to encourage innovation will play an important guiding role for enterprises to encourage employees' innovation. Enterprises incentive to employees has significant effect to promote the enterprise's innovation performance [6].

In addition, when the government support SMEs' innovation, they often put forward certain requirements about SMEs own investment. These requirements will increase mandatory role of technological innovation for enterprises. And it will promote enterprises to adopt various measures to enliven the innovation behaviour from the outside.

\subsection{Framework of government behaviours on SMEs Innovation}

Based on the analysis, we put forward the framework of government behaviours on SMEs Innovation show in figure 1.

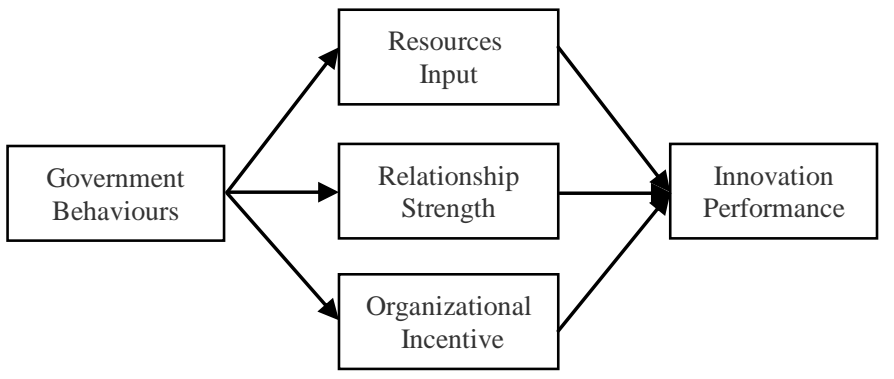

Fig.1 Framework of Government Behaviours on SMEs Innovation

\section{Conclusion}

Based on the analysis above, we know that government behaviours can help SMEs to increase resources input and improve the innovation performance, government behaviours can increase the strength of the relationship between enterprises and government and then improve the innovation performance, and government behaviours help SMEs to strengthen the organizational incentive and then improve innovation performance.

From the perspective of the government, as the makers of innovation policy and the main distribution of social resources, they can help SMEs in many ways. On one hand, the government needs to stimulate SMEs to increase investment in innovation; on the other hand, more attention should be paid to the construction of innovation incentive mechanism for SMEs. So as to promote SMEs have more innovation power by various preferential policies of the government. From the perspective of the enterprise, as the main body of innovation and execution by innovation policy support should do more innovations. On the one hand, they should further increase investment in innovation resources; on the other hand, they should actively implement various incentive policies to help active organization innovations. In the process of government help SMEs' innovation activities, the two sides should establish the relationship more harmonious and stable.

\section{References}

[1] Wang Jinzhao. Research on the innovation of SMEs. Wuhan: doctoral dissertation of Wuhan University of Technology, 2009.

[2] www.gov.cn. Notification of the issuance designated type standard of SMEs. 2011-07-04.

[3] Bi Shoufeng, Kong Xinxin. Research on the main problems of innovation for SMEs. Chinese Technology Forum, 2012 (9): 83-88.

[4] Wang Yaling. Construct the government support system for SMEs innovation-- Based on the analysis of "Pigs Game" model. Productivity research, 2008 (11): 135-137.

[5] Lin Ruhai, Peng Weixiang. Research on the innovation theory of firm and its significance in appraising enterprise innovation ability. Science and Technology Management, 2009 (11): 118-121.

[6] Li Weiming et al.. An Empirical Study on the influence of technology innovation policy on innovation performance of SMEs - take enterprise resource investment and organization incentive as intermediary variable. Science of Science and Management of Science and Technology, 2008 (9): 61-65.

[7] Yuan Jianhong, Gong Tianyu, Guo Jinfen. Evaluation the innovation policy effect on SMEs. Journal of Southeast University (Philosophy and Social Sciences Edition), 2012 (4): 40-45.

[8] Tang Linjia, Chi Renyong, Luo Xiujuan. Innovation policy frontier of the SMEs. Science of Science and Management of Science and Technology, 2013 (8): 138-147.

[9] Ao Jianmeng. Analysis of the role of government in SMEs' innovation -foreign experience and Guangdong's choice. Market Modernization, 2006 (8): 235-236.

[10] Long Jing, Liu Haijian. Effects of government power operation mode to the innovation performance of SMEs -- Based on the perspective from the relationship between business and government. Science of Science and Management of Science and Technology, 2012 (5): 96-105. 